\title{
Preventing Advanced Stages of Disease in Samoa: A Literature Review
}

Annette Kaspar ${ }^{1 *}$, Aleki Fuimaono ${ }^{2}$, Shaun Mauiliu ${ }^{2}$, Sione Pifeleti ${ }^{1,2}$, and Junior Posini ${ }^{2}$

${ }^{1}$ ENT Department, Tupua Tamasese Meaole Hospital, Ministry of Health, Apia, SAMOA, South Pasific

${ }^{2}$ Surgery Department, Tupua Tamasese Meaole Hospital, Ministry of Health, Apia, SAMOA, South Pacific

*corresponding author, email: annette.kaspar@gmail.com;

\section{ARTICLE INFO}

Article history

Received 08/25/2021

Revised 09/27/2021

Accepted 10/01/2021

Keywords

Pacific Islands

Surgery

Filarial hydrocele

SUFE

H. pylori-induced gastric cancer

\section{ABSTRACT}

Background: Surgeons are scarce in the Pacific Islands, and improvements to public and primary health care services should reduce the burden of avoidable surgical interventions. Three communicable and non-communicable diseases of public health concern in Samoa are filariasis, childhood overweight/obesity, and Helicobacter pylori ( $H$. pylori)-induced gastric cancer. Strengthening existing public and primary health care strategies for these issues should, in turn, reduce the avoidable surgical burden of Hydrocelectomy for filarial hydrocele, in-situ pinning for Slipped Upper Femoral Epiphysis (SUFE), and endoscopic Esophago-Gastro-Duodenoscopy (EGD) for the differential diagnosis of $H$. pylori-induced gastric pathologies. This study aimed to perform a literature review of these conditions requiring surgical intervention in the Pacific Islands to contribute recommendations to the current public and primary health care activities in Samoa. Method: A literature review was conducted using the PubMed and ScienceDirect databases. The primary search strategy utilized the terms and keywords "Pacific Islands"; "Filarial Hydrocele"; "SUFE"; "H. pylori-induced gastric pathology"; and their relevant synonyms. Inclusion criteria: the study population were Pacific Islanders residing in the Pacific Islands, and the study investigated presentation, etiology, epidemiology, treatment, and/or management for the three diseases of interest. Articles published before 2000 were excluded. Results: There was only one journal article that met the inclusion criteria. There is virtually no research literature on the current state of these preventable surgical conditions among the population residing in the Pacific Islands. Conclusion: Data are needed to inform evidence-based policy formulation and implementation. The surgical voice should positively contribute to public health efforts.

This is an open access article under the CC-BY-SA license.

\section{Introduction}

The Sustainable Development Agenda highlights the central role of public and primary health care in the improvement of national health and well-being. This approach is essential in the Pacific Island region where countries bear the double-burden of both communicable and noncommunicable diseases for all age groups. With the support of international collaborations and partnerships, Pacific Island nations are currently working towards strengthening public and primary health care infrastructures in order to achieve optimal universal health coverage for all. The COVID-19 pandemic provided a catalyst to further these aims, and it is desirable for the progress made during COVID-19 preparedness efforts to healthcare infrastructure and delivery to continue into the future. 
Samoa is a Polynesian nation of the Pacific Islands that has remained COVID-19 free to date through the successful implementation of strict public health and border control measures. The current COVID-19 preparedness efforts are to be commended, and it is anticipated that the improvements to the health system and health service delivery infrastructures will continue beyond the COVID-19 pandemic. Three public health issues that should benefit from these measures are filariasis, childhood overweight/obesity, and Helicobacter pylori (H. pylori) -induced gastric cancers.

The aim of the present study is to draw attention to these three public health issues and the avoidable burden of surgical interventions/procedures associated with them. The Surgical Unit of the national referral Tupua Tamasese Meaole Hospital currently consists of three senior general surgeons and one surgical registrar. Each surgeon also has additional areas of specialization, including sepsis/infections, orthopedics, and ENT/endoscopy. A significant proportion of the surgical caseload could be avoided through improved public and primary health care measures.

Lymphatic filariasis (LF) has a long and well-documented history in the Pacific Islands [1,2]. The Pacific Programme to Eliminate Lymphatic Filariasis (PacELF) was established in 1999, and there have been both successes and challenges to achieving elimination goals [3]. While prevention, treatment, and control strategies for LF are well-known and effective [4], Mass Drug Administration (MDA) for the elimination of LF depends on community compliance and successful health delivery logistics [5]. Where MDA is suboptimal, there is the risk of LF drug resistance and LF re-emergence $[1,6]$. From a surgical perspective, the significant burden of the avoidable surgical caseload is hydrocelectomy due to lymphatic filarial hydrocele.

Childhood overweight/obesity is a major public health crisis throughout the Pacific Islands [7]. This region is reported to have among the highest global rates of overweight/obesity [8], usually explained by a number of contributing factors, including lifestyle changes associated with economic development [9-13]. Given that addressing childhood overweight/obesity is a priority under the Sustainable Development Goal Agenda, significant effort is devoted to public health promotion activities regarding healthy eating and physical activity. In Samoa, school-based health education on healthy living is delivered through the PEN FaaSamoa Initiative that aims to reduce national levels of non-communicable diseases [14]. School-based programs are also reported from other parts of the Pacific region. Childhood overweight/obesity is the leading cause of Slipped Upper Femoral Epiphysis (SUFE), an orthopedic disorder that may only be remedied through surgical intervention [15]. From a surgical perspective therefore, a significant burden of the avoidable surgical caseload is in-situ pinning of the affected SUFE hip due to childhood overweight/obesity.

Gastric cancer is one of the highest causes of cancer-related deaths worldwide [16]. The carcinogenesis of this inflammation-associated cancer begins with $H$. pylori bacterial infection [17]. The current opinion recommends eradication of $H$. pylori as a public health measure to reduce the burden of gastric cancer $[16,18]$, as well as other major $H$. pylori-induced gastric pathologies, such as peptic ulcers and precancerous stages of the gastric disease $[19,20]$. A study from New Caledonia demonstrated that migration contributes to the diversity of the $H$. pylori bacterial pathogen. Endoscopic Esophago-Gastro-Duodenoscopy (EGD) is the recommended surgical procedure for the investigation of gastric symptoms suggestive of $H$. pylori-associated gastric pathologies. At the time of writing, endoscopy procedures are performed by only one of the general surgeons in Samoa as the operating theatre schedule permits, as well as one physician from the outpatient clinic. From a surgical perspective, improved primary and public health management of $H$. pylori-induced gastric pathologies would significantly reduce the referral rate, waiting list, and EGD caseload.

The following literature review was, therefore, performed to enable evidence-based public/primary health policy formulation and implementation for these three health conditions that constitute a significant proportion of the surgical caseload at the Surgical Unit in Samoa: filarial hydrocele, slipped upper femoral epiphysis (SUFE), and $\mathrm{H}$. pylori-induced gastric pathologies. These conditions may already be addressed through existing public and primary health care platforms and initiatives. The literature review should further inform current efforts, and improvements to public/primary health care should reduce the burden of avoidable surgical procedures. This paper should also add a surgical voice to the numerous discussions surrounding public health activities in the Pacific Islands. 


\section{Materials and Method}

A literature review was conducted utilizing PubMed and ScienceDirect databases. The main search strategy used the terms and keywords "Pacific Islands"; "Filarial Hydrocele"; "Slipped Upper Femoral Epiphysis"; " $H$. pylori-associated gastric disease"; and their relevant synonyms (i.e., "Scrotal filariasis"; "Slipped Capital Femoral Epiphysis"; "H. pylori-induced gastric disease"): "Pacific Islands"[MeSH Terms] OR ("Pacific"[All Fields] AND "Islands"[All Fields]) OR "Pacific Islands"[All Fields]; "Filarial Hydrocele"[MeSH Terms] OR ("Filarial"[All Fields] AND "Hydrocele"[All Fields]) OR "Filarial Hydrocele"[All Fields]; "Slipped Upper Femoral Epiphysis"[MeSH Terms] OR ("Femoral"[All Fields] AND "Epiphysis"[All Fields]) OR "Slipped Upper Femoral Epiphysis"[All Fields]; "H. pylori-associated gastric disease" [MeSH Terms] OR ("H. pylori"[All Fields] AND "Gastric Disease"[All Fields]) OR " $H$. pylori-associated gastric disease"[All Fields]. Following this search strategy, titles and abstracts were read and reviewed, and, when appropriate, included for further study. The selected articles were read completely, and their references were hand-searched.

The following inclusion criteria were used to assess article suitability for this review, such as the study population was Pacific Islanders residing in the Pacific Islands, and the study investigated presentation, etiology, epidemiology, treatment, and/or management for the three diseases of interest. Given the public health measures implemented under the Millennium Development Goals 2000-2015 (MDGs), articles published before 2000 were excluded. As per journal guidelines, articles published within the last 5 years only were acceptable.

\section{Results and Discussion}

Only one journal article was found that met the inclusion criteria. While there are articles describing these conditions among Pacific Islanders living in New Zealand and Australia, our interest is in determining public health recommendations for the Samoan context. The one journal article identified described the burden of hydrocele assessed from medical and surgical records in the lymphatic filariasis endemic country of Samoa [21]. Between 2006 and 2013, there were 535 suspected cases of hydrocele among men aged 18 years and older, and 328 cases were subsequently confirmed as hydrocele. Only $4 \%$ of patients' records documented filarial hydrocele as the differential diagnosis. Surgical intervention was performed for $60.7 \%$ of cases, where the average age of the patient was 48.2 years.

There were no articles pertaining to SUFE or $H$. pylori-associated gastric pathologies in a Pacific Islander population residing in the Pacific Islands. However, there was one article describing SUFE among adolescents of Pacific Islander ethnicity residing in New Zealand [22]. There were two articles on $\mathrm{H}$. pylori among Pacific Islanders living in New Zealand [23], but only one was published within the last five years.

There is virtually no research on these conditions requiring surgical intervention in the Pacific Islands. From the surgeon's perspective, it is essential to include surgical caseload reports in the monitoring and evaluation of public/primary health care measures, as progression of disease to advanced stages requiring surgical intervention often highlights where public/primary health care strategies need to be strengthened or re-evaluated. Formal review and research journal publication of the three health issues highlighted in this paper should prove useful to addressing lymphatic filariasis, childhood overweigh/obesity, and $H$. pylori-associated gastric disease in the Pacific Islands.

As mentioned above, these three public health issues are already important priorities for the Pacific Island region. Not only will their elimination or improved management contribute to the physical well-being, it will also positively impact on the mental and socio-emotional health of the individual and their families [24]. Future strategies may include the use of mobile technologies and targeted screening programs, and must include community engagement and consultation [25-29]. There are also exciting developments in the field of Type 2 Diabetes Mellitus reversal/remission which should impact health policies regarding NCDs and overweight/obesity among adolescents [30].

\section{Conclusion}

There is virtually no research literature on the current state of these preventable surgical conditions among populations residing in the Pacific Islands. Data are needed to inform evidencebased policy formulation and implementation. The surgical voice should make a positive contribution to strengthening current public and primary health care initiatives, both in Samoa and among our Pacific Island neighbors. 
Acknowledgments: None.

\section{Declaration}

Conflicts of Interest: The authors declare no conflict of interest.

\section{References}

1. Gordon CA, Jones MK, McManus DP. The History of Bancroftian Lymphatic Filariasis in Australasia and Oceania: Is There a Threat of Re-Occurrence in Mainland Australia? Tropical Medicine and Infectious Disease. 2018;3:58. doi: https://doi.org/10.3390/tropicalmed3020058

2. Collaborators NTD. The Global Distribution of Lymphatic Filariasis, 2000-18: A Geospatial Analysis. Lancet Global Health. 2020;8:e1186-e94. doi: https://doi.org/10.1016/s2214$109 \times(20) 30323-5$

3. Yajima A, Ichimori K. Progress in the Elimination of Lymphatic Filariasis in the Western Pacific Region: Successes and Challenges. International Health. 2021;13(Suppl. 1):S10-S6. doi: https://doi.org/10.1093/inthealth/ihaa087

4. Turner HC. Health Economic Analyses of the Global Programme to Eliminate Lymphatic Filariasis. International Health. 2021;13(Suppl. 1):S71-S4. doi: https://doi.org/10.1093/inthealth/ihaa095

5. Krentel A, Gyapong M, McFarland DA, Ogundahunsi O, Titaley CR, Addiss DG. Keeping Communities at the Centre of Efforts to Eliminate Lymphatic Filariasis: Learning From the Past to Reach A Future Free of Lymphatic Filariasis. International Health. 2021;13(Suppl. 1):S55-S9. doi: https://doi.org/10.1093/inthealth/ihaa086

6. Gyapong JO, Owusu IO, Vroom FBd-C, Mensah EO, Gyapong M. Elimination of Lymphatic Filariasis: Current Perspectives on Mass Drug Administration. Research and Reports in Tropical Medicine. 2018;9:25-33. doi: https://doi.org/10.2147/rrtm.s125204

7. Ampofo AG, Boateng EB. Beyond 2020: Modelling Obesity and Diabetes Prevalence. Diabetes Research and Clinical Practice. 2020;167:108362. doi: https://doi.org/10.1016/j.diabres.2020.108362

8. NCD. Worldwide Trends In Body-Mass Index, Underweight, Overweight, and Obesity From 1975 to 2016: A Pooled Analysis of 2416 Population-Based Measurement Studies in 128.9 Million Children, Adolescents, And Adults. Lancet. 2017;390:2627-42. doi: https://doi.org/10.1530/ey.15.13.20

9. Cauchi JP, Bambrick H, Correa-Velez I, Moncada S. 'White Flour, White Sugar, White Rice, White Salt: Barriers to Achieving Food and Nutrition Security in Kiribati. Food Policy. 2021;101:102075. doi: https://doi.org/10.1016/j.foodpol.2021.102075

10. Guell C, Brown CR, lese V, Navunicagi O, Wairiu M, Unwin N. "We used to get food from the garden". Understanding Changing Practices of Local Food Production and Consumption in Small Island States. Social Science \& Medicine. 2021;284:114214. doi: https://doi.org/10.1016/j.socscimed.2021.114214

11. Dancause KN, Olszowy KM. Identifying Actionable Lifestyle Risk Factors For Obesity Research and Intervention: Challenges and Opportunities For Pacific Island Health Researchers. The Lancet Regional Health - Western Pacific. 2020;4:1000040. doi: https://doi.org/10.1016/j.lanwpc.2020.100040

12. Frayon S, Wattelez G, Paufique E, Nedjar-Guerre A, Serra-Mallol C, Galy O. Overweight in the Pluri-Ethnic Adolescent Population of New Caledonia: Dietary Patterns, Sleep Duration and Screen Time. The Lancet Regional Health - Western Pacific. 2020;2:1000025. doi: https://doi.org/10.1016/j.lanwpc.2020.100025

13. Dye TDV, Sy A, Albert $P$, Cash H, Hadley J, Tomeing T, et al. Criticial Medical Ecological Perspectives on Diabetes in the Pacific Islands: Colonialism, Power, and Balance in the HumanEnvironment Interaction Over Time. The Lancet Global Health. 2018;6(S36). doi: https://doi.org/10.1016/s2214-109x[18]30165-7

14. Saeedi P, Petersohn I, Salpea P, Malanda B, Karuranga S, Unwin N, et al. Global and Regional Diabetes Prevalence Estimates For 2019 and Projections For 2030 And 2045: Results from the International Diabetes Federation Diabetes Atlas, 9th edition. Diabetes Research and Clinical Practice. 2019;157:107843. doi: https://doi.org/10.1016/j.diabres.2019.107843

15. Peck DM, Voss LM, Voss TT. Slipped Capital Femoral Epiphysis: Diagnosis and Management. American Family Physician. 2017;95(12):779-84.

https://doi.org/10.1093/med/9780199550647.003.013019

16. Wu J-Y, Lee Y-C, Graham DY. Eradication of Helicobacter pylori to Prevent Gastric Cancer: A Critical Appraisal. Expert Review of Gastroenterology \& Hepatology. 2019;13[1]:17-24. doi: https://doi.org/10.1080/17474124.2019.1542299 
17. Amieva M, Peek Jr RM. Pathobiology of Helicobacter pylori-induced Gastric Cancer. Gastroenterology. 2016;150[1]:64-78. doi: https://doi.org/10.1053/j.gastro.2015.09.004

18. Lee Y-C, Chiang T-H, Chou C-K, Tu Y-K, Liao W-C, Wu M-S, et al. Association Between Helicobacter Pylori Eradication and Gastric Cancer Incidence: A Systematic Review and MetaAnalysis. Gastroenterology. https://doi.org/10.1053/j.gastro.2016.03.018 2016;150:1113-24 doi:

19. Bravo D, Hoare A, Soto C, Valenzuela MA, Quest AFG. Helicobacter pylori in Human Health and Disease: Mechanisms For Local Gastric and Systemic Effects. World Journal of Gastroenterology. 2018;24(28):3071-89. doi: https://doi.org/10.3748/wjg.v24.i28.3071

20. de Brito BB, da Silva FAF, Soares AS, Pereira VA, Santos MLC, Sampaio MM, et al. Pathogenesis and Clinical Management of Helicobacter Pylori Gastric Infection. World Journal of Gastroenterology. 2019;25(37):5578-89. doi: https://doi.org/10.18535/jmscr/v5i9.126

21. Ah Leong-Lui TA, Graves PM, Naseri T. Burden of Hydrocele Assessed From Medical and Surgical Records in A Lymphatic Filariasis Endemic Country, Samoa. Tropical Medicine and Health. 2019;47:51. doi: https://doi.org/10.1186/s41182-019-0179-0

22. Navarre P. Slipped Capital Femoral Epiphysis: A Review of the New Zealand literature. Journal of Bone and Joint Surgery American Volume. 2020;102(Suppl. 2):8-14. doi: https://doi.org/10.2106/jbjs.20.00066

23. Teng AM, Blakely T, Baker MG, Sarfati D. The Contribution of Helicobacter pylori to Excess Gastric Cancer in Indigenous And Pacific Men: A Birth Cohort Estimate. Gastric Cancer. 2017;20:752-5. doi: https://doi.org/10.1007/s10120-016-0671-8

24. Hofstraat K, van Brakel WH. Social Stigma Towards Neglected Tropical Diseases: A Systematic Review. International Health. 2016;8(Suppl. 1):i53-i70. doi: https://doi.org/10.1093/inthealth/ihv071

25. Srividya A, Subramanian S, Jambulingam P, Vijayakumar B, Raja JD. Mapping and Monitoring For A Lymphatic Filariasis Elimination Program: A Systematic Review. Research and Reports in Tropical Medicine. 2019;10:43-90. doi: https://doi.org/10.2147/rrtm.s134186

26. Carrion C, Robles N, Sola-Morales O, Aymerich M, Postigo JAR. Mobile Health Strategies to Tackle Skin Neglected Tropical Diseases with Recommendations From Innovative Experiences: Systematic Review. JMIR mHealth and uHealth. 2020;8(12):e22478. doi: https://doi.org/10.2196/preprints.22478

27. Teng AM, Kvizhinadze G, Nair N, McLeod M, Wilson N, Blakely T. A Screening Program to Test and Treat For Helicobacter Pylori Infection: Cost-Utility Analysis By Age, Sex And Ethnicity. BMC Infectious Diseases. 2017;17:156. doi: https://doi.org/10.1186/s12879-017-2259-2

28. Collier AF, Daiss S, Temengil E, Russell SC, Miller JC, Renguul FM. Developing an Obesity Intervention in Micronesia: From Needs Assessment to Planning. Evaluation and Program Planning. 2018;69:33-42. doi: https://doi.org/10.1016/j.evalprogplan.2018.04.003

29. Frayon S, Cavaloc Y, Wattelez G, Cherrier S, Lerrant $Y$, Ashwell M, et al. Potential for Waist-toHeight Ratio to Detect Overfat Adolescents From A Pacific Island, Even Those Within the Normal BMI Range. Obesity Research \& Clinical Practice. 2018;12:351-7. doi: https://doi.org/10.1016/j.orcp.2017.12.001

30. Taylor R, Valahbji J, Aveyard P, Paul D. Prevention and Reversal of Type 2 Diabetes: Highlights From A Symposium at the 2019 Diabetes UK Annual Professional Conference. Diabetic Medicine. 2019;36:358-65. doi: https://doi.org/10.1111/dme.13892 